\title{
Differential disruption of genomic integrity and cell cycle regulation in normal human fibroblasts by the HPV oncoproteins
}

\author{
Alicia E. White, ${ }^{1,2}$ Elizabeth M. Livanos, ${ }^{1}$ and Thea D. Tlsty ${ }^{1-3}$ \\ ${ }^{1}$ Lineberger Comprehensive Cancer Center, Department of Pathology and ${ }^{2}$ Curriculum in Genetics and Molecular Biology, \\ University of North Carolina at Chapel Hill, School of Medicine, Chapel Hill, North Carolina 27599-7295 USA
}

\begin{abstract}
Genomic integrity is maintained by a network of cellular activities that assess the status of the genome at a given point in time, provide signals to proceed with or halt cell cycle progression, and provide for repair of damaged DNA. Mutations in any part of these pathways can have the ultimate effect of disturbing chromosomal integrity. Recent work suggests that p53 performs this integrator function in mammalian cells. Our present study demonstrates that in mortal cells, the expression of E6 and E7 viral oncoproteins of type 16 human papillomavirus each disrupts the integration of these signals by diverged pathways. Cells expressing E6 protein, which binds and degrades the $\mathbf{5 3}$ protein, exhibited alterations in cell cycle control when placed in drug and displayed the ability to amplify the CAD gene. The expression of E7, which binds different cellular proteins important for transformation, including $\mathbf{R b}$, led to a p53-independent alteration in cell cycle control, a widespread cytocidal response, and polyploidy as a mechanism of drug resistance. These results demonstrate that diverse perturbations of molecular pathways can have different effects on chromosomal integrity.
\end{abstract}

[Key Words: Genomic instability; gene amplification; HPV 16; cell cycle control; p53; pRb]

Received December 15, 1993; revised version accepted January 21, 1994.

Loss of genomic integrity is a hallmark of neoplastic cells and fuels the multistep process of carcinogenesis. Changes in genomic integrity are seen when cells are transformed spontaneously, virally, or with chemicals. In studying the loss of genomic integrity, our previous work has focused on spontaneously transformed cells (both rodent and human) and their ability to exhibit one form of genetic instability, gene amplification. Gene amplification is an increase in gene copy number of a given locus and occurs spontaneously at a high frequency $\left(10^{-6}-10^{-3}\right)$ in preneoplastic and neoplastic cells (Sager et al. 1985; Otto et al. 1989; Tlsty et al. 1989; Jonczyk et al. 1993|. In contrast, gene amplification is undetectable in normal cells $\left(<10^{-9}\right)$ as measured by the ability to become resistant to the drug $N$-(phosphonoacetyl)-L-aspartate (PALA) (Tlsty 1990; Wright et al. 1990). Genetic analysis of this property indicates that the ability to amplify is a recessive genetic trait (Tlsty et al. 1992). These data suggest that normal cells have a gene, or set of genes, that suppresses amplification. In our search for possible candidate genes, the p53 gene emerged as an important modulator of gene amplification frequency as well as other genomic alterations.

\footnotetext{
${ }^{3}$ Corresponding author.
}

One method of maintaining genomic integrity involves the action of cell cycle checkpoint genes, which integrate proper sensing of environmental signals and appropriate cellular responses. Data to support this idea come from several sources, most importantly, studies of genes in yeast that control cell cycle progression. Hartwell (Hartwell and Weinert 1989) has demonstrated that some of these genes, called checkpoint genes, coordinate cell cycle progression with cellular signals and allow for the maintenance of chromosomal integrity. In mammalian cells, the $\mathrm{p} 53$ protein is part of a pathway that allows cells to arrest their cell cycle progression when conditions for growth are unfavorable, such as the presence of antimetabolites (Livingstone et al. 1992; Yin et al. 1992). One consequence of this action is to prevent the emergence of drug-resistant colonies (Livingstone et al. 1992; Yin et al. 1992). Studies by Kastan and co-workers implicate p53 in a similar activity, the cellular response to $\gamma$-radiation (Kastan et al. 1991; Kuerbitz et al. 1992). In this capacity it is suggested that p53 receives information that DNA damage has occurred and mediates, through the possible action of GADD 45, growth arrest after DNA damage in normal cells. Hence, p53 exhibits several functions of a checkpoint gene in mammalian cells and appears to play a key role in maintaining genomic integrity. Further studies demonstrated that some 
human tumorigenic cells showed loss of genomic integrity while containing two wild-type $\mathrm{p} 53$ alleles, suggesting that alternate pathways or alternate regulation of $p 53$ can bypass the role of $\mathrm{p} 53$. Therefore, mutations in $\mathrm{p} 53$ protein are not the sole determinant for the regulation of genomic integrity (Livingstone et al. 1992).

Ideally, to investigate events that promote the aquisition of genomic instability, a model system that starts with a normal cell and disrupts genomic integrity at a defined point was needed. The DNA tumor viruses provided such a system. Our previous studies (Jonczyk et al. 1993) demonstrate that virally transformed cells possess the ability to amplify. In this study we used the human papillomavirus (HPV) type 16 (HPV-16) to determine when, after expression of viral oncoproteins, the cells acquire the ability to amplify genes. The HPVs include numerous genotypes that induce benign genital warts or tumors of the epithelial or fibroepithelial components of skin or mucosa. Numerous clinical, epidemiological, and molecular evidence associates specific viral types with the formation of carcinomas of the genital and oral mucosa (zur Hausen 1991). Some HPV types such as 16 , $18,31,33,39$ are referred to as "high risk" because of their association with cervical carcinoma. Other types such as 6 and 11 associated with benign lesions are termed "low risk."

Although frequently found in cervical carcinoma cells, the presence of a high risk HPV type is not sufficient to trigger malignant progression. The virus may be present with a long latency and only rarely does progression of genital lesions into carcinomas occur (zur Hausen 1991). Expression of two viral proteins, E6 and E7, is consistently found in the majority of cervical carcinomas and derived cell lines (Schwarz et al. 1985; Smotkin and Wettstein 1986; Baker et al. 1987; Wilczynski et al. 1988). Expression of these two viral proteins is sufficient to efficiently immortalize human keratinocytes and extend the normal life span of human fibroblasts (HawleyNelson et al. 1989; Munger et al. 1989a; Watanabe et al. 1989; Dhanwada et al. 1992). The HPV-16 E6 gene product binds and aids in the degradation of $\mathrm{p} 53$ (Scheffner et al. 1990; Werness et al. 1990/ while the E7 gene product binds a set of proteins that includes hypophosphorylated pRb, p107, pl30, and cyclin A (Dyson et al. 1989, 1992; Davies et al. 1993; Tommasino et al. 1993). The mechanistic consequences of these protein couplings on the neoplastic process is under intense investigation.

In this study we examine amplification potential, chromosomal integrity, and cell cycle perturbations in normal human fibroblasts that have been infected with genes that code for high risk HPV- 16 and low risk HPV- 6 viral oncoproteins. We found that normal human fibroblasts that expressed type 16 E6/E7 together or E6 alone acquired the ability to generate PALA-resistant colonies by $\mathrm{CAD}$ gene amplification immediately after viral infection. In contrast, the majority of cells expressing the E7 protein alone underwent a rapid cytocidal response when placed in drug, with rare PALA-resistant variants acquiring multiple copies of chromosome 2 (aneuploidy) as a mechanism of drug resistance. In each case, these virally altered cells have clearly acquired genetic instability prior to immortalization, as all of these cells eventually underwent cellular senescence. Normal human fibroblasts carrying type 6 low risk HPV proteins do not disrupt the genomic integrity of NHF. Our data suggest a physiological consequence of these interactions and their importance in viral carcinogenesis; both results relate to the maintenance of genomic integrity.

\section{Results}

\section{Generation of HPV-16 oncoprotein-infected NHF}

Introduction of the viral oncoproteins from HPV-16 into normal human fibroblasts (Materials and methods) was accomplished by use of a recombinant retroviral system. Retroviral constructs contained the gene coding for neomycin resistance alone, or in combination with the open reading frames (ORFs) for HPV-16 E6/E7 together, or each of the viral oncoproteins individually (Fig. 1). Normal human fibroblasts at population doubling (PDL) 33 (neo, E6) and PDL 36 (E6/E7, E7) were infected at high titer with the described retroviral vectors and selected in the neomycin analog G418 sulfate. Similar numbers of G418 sulfate-resistant colonies arose from each retroviral infection. Resistant cells were pooled, resulting in the cell populations NHF neo, NHF16 E6/E7, NHF16 E6, and NHF16 E7. Radioimmunoprecipitation of HPV-16 E6 and E7 proteins in the cell populations demonstrated their expression, with the E6/E7-infected population expressing both viral oncoproteins and the E6 and E7-infected populations expressing the appropriate individual proteins (data not shown; Materials and methods; Halbert et al. 1991). Analysis of p53 and pRB protein by Western blot revealed decreased p53 protein levels in E6-expressing cells and decreased pRb levels in E7-expressing cells (data not shown). Oncogene-expressing cells were examined for the effect of the viral proteins on genomic integrity and the cellular potential to amplify.

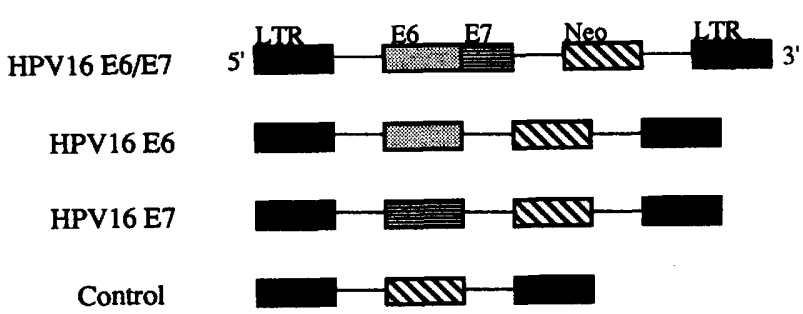

Figure 1. Recombinant retroviral vectors containing HPV-16 sequences. Expression of the HPV oncoproteins in NHF was accomplished by infection of the cells with retroviral vectors. The viral particles contained Moloney murine leukemia virus promoter-enhancer sequences (LTR, solid box), HPV-16 E6/E7 sequences together or separately (E6, stippled box; E7, horizontally striped box $\mid$, and under control of the SV40 promoter, the neomycin resistance gene (Neo, hatched box). Integration of the viral sequences into the NHF genome allowed stable expression of HPV protein(s) and conferred resistance to the neomycin analog G-418 sulfate in the infected cell and progeny cells. (Diagram modified from Halbert et al. 1991). 
Characterization of chromosome complements in HPVinfected NHF

Chromosome complements were examined in the uninfected and HPV-infected NHF cells (Table 1). The karyotypic stability of the five cell populations was examined during their extended propagation in culture, using samples taken 20 PDLs after the viral oncogene-expressing populations were selected as well as prior to their senescence in culture. Normal diploid karyotypes were observed in the parental NHF cells at both early passage and at late passage close to senescence. At early passage after infection with the indicated oncoprotein-coding genes, the NHF neo, NHF16 E6, and NHF16 E7 cells produced karyotypes that were indistinguishable from the parental NHF cells (Table 1). All three had a basic normal karyotype with no rearrangements or telomeric association. The karyotypes of the NHF16 E6/E7 cells at early passage were found to have telomeric association in $8 \%$ of the cells and rearrangements in $6 \%$ of the cells. The telomeric association figures seen were simple, each consisting of two recognizable chromosomes attached at their telomeres with no noticeable loss or gain of chromatin at the junctions. When the karyotypes of the E6/ E7- and E6-expressing cells were examined late in passage, they were found to have numerous genomic rearrangements. Few of the cells were diploid, and most contained multiple rearrangements, telomeric associations, and gross aneuploidy (T. Tlsty, in prep.). In contrast to the E6-expressing cells, the karyotypes of the E7-expressing cells at late passage were completely diploid.

\section{Characterization of growth control in HPV-} infected NHF

Cell morphology, PDL time, mortality, and behavior at confluence were examined in the uninfected and HPV- 16-infected NHF cells (Table 2). Morphologically, the HPV protein-expressing cells were indistinguishable from each other. Although similar to the uninfected NHF, all three of the HPV-infected cell populations were smaller and less extended than the NHF parental cells (Fig. 2). The PDL time of each cell population was determined. The parental NHF and NHF neo-containing cells had similar PDL times when grown in standard media. The NHF cells that expressed both viral oncoproteins demonstrated a slightly longer doubling time (Table 2). Past studies have indicated that individually, the E6 or E7 proteins of HPV-16 do not significantly influence the life span nor immortalize NHF, but together, the proteins can efficiently extend the life span of NHF compared with that of normal controls (Watanabe et al. 1989). In agreement with these studies, we found the E6and E7-expressing cells senesced between 78 and 88 PDL, whereas in the E6/E7-expressing cells an extension of life span of $\sim 20$ PDL compared with NHF was noted (Table 2). Immortalization of HPV oncoprotein-expressing fibroblasts is rare or negligible (Shay et al. 1993) and was not observed in this set of experiments.

The oncoprotein-expressing cells demonstrated rather striking responses to growth conditions at confluence. As normal diploid fibroblasts such as NHF become confluent, they become tightly packed in a monolayer and cease proliferation. This contact inhibition results in a cessation of progression through the cell cycle with the cells arrested in $a \mathrm{G}_{0}$ state indefinitely. The cells containing E6/E7 together or E6 alone demonstrated a response that was similar to each other but slightly different than that exhibited by parental NHF. The cells formed a monolayer, and for the most part, arrested in growth, but infrequent mitotic figures could be observed even several days after the cells achieved confluence (Fig. $2 D, F)$. The cells could be held in this state for long periods of time (months). Interestingly, the E7-expressing cells demonstrated an entirely different response after

Table 1. Karyotypic characterization of NHF and HPV protein-expressing fibroblasts

\begin{tabular}{|c|c|c|c|c|c|}
\hline Cell population & $\begin{array}{l}\text { Diploid }^{a} \\
(46 \pm 2)\end{array}$ & $\begin{array}{l}\text { Tetraploid } \\
(92 \pm 2)\end{array}$ & Aneuploid & $\begin{array}{l}\text { Telomeric } \\
\text { association }^{\mathrm{b}}\end{array}$ & $\begin{array}{l}\text { Translocation } \\
\text { rearrangement }\end{array}$ \\
\hline \multicolumn{6}{|l|}{ Early passage populations } \\
\hline NHF & 100 & 0 & 0 & 0 & 0 \\
\hline NHF neo (pd 40) & 94 & 6 & 0 & 0 & 0 \\
\hline NHF16 E6/E7 (pd 46) & 96 & 0 & 4 & 8 & 6 \\
\hline NHF16 E6 (pd 56) & 100 & 0 & 0 & 0 & 0 \\
\hline NHF16 E7 (pd 50) & 96 & 4 & 0 & 0 & 0 \\
\hline \multicolumn{6}{|l|}{ PALA-resistant subclones } \\
\hline NHF16 E6/E7 Cl & 86 & 0 & 14 & 34 & 80 \\
\hline NHF16 E6/ E7 C3 & 74 & 2 & 24 & 48 & 72 \\
\hline NHF16 E6 C1 & 48 & 6 & 46 & 66 & 86 \\
\hline NHF16 E6 C4 & 78 & 2 & 20 & 54 & 86 \\
\hline
\end{tabular}

A minimum of 50 metaphase spreads was examined from each cell population. The numbers indicate the percentage of cells in each category.

anfrequently, in normal cells there is a random loss of a single chromosome or the observation of a tetraploid cell. These deviations are found in $<10 \%$ of normal cells. Our observations are in keeping with those reported for normal human fibroblasts and lymphocytes in the literature (Aurias 1993).

${ }^{b}$ Telomeric association is defined as end-to-end fusion of chromosomes. 
Table 2. Growth properties and frequency of PALA resistance

\begin{tabular}{llllcrc}
\hline Cell name & $\begin{array}{l}\text { PDL }^{\mathbf{a}} \\
\text { time }(\mathrm{hr})\end{array}$ & $\begin{array}{l}\text { Total } \\
\text { PDL }\end{array}$ & $\begin{array}{l}\mathrm{PE}^{\mathrm{b}} \\
(\%)\end{array}$ & $\begin{array}{l}\mathrm{PALA}^{\mathrm{c}} \\
\mathrm{LD}_{50}(\mu \mathrm{M})\end{array}$ & $\begin{array}{l}\text { PALA } \\
\left(9 \times \mathrm{LD}_{50}\right)\end{array}$ & $\begin{array}{l}\text { PALA resistance } \\
\text { frequency }\left(9 \times \mathrm{LD}_{50}\right)\end{array}$ \\
\hline NHF & $20 \pm 0.52$ & 72 & $33 \pm 0.05$ & $13 \pm 1$ & 117 & $\left(<1 \times 10^{-7}\right)$ \\
NHF neo & $22 \pm 2.9$ & 70 & $30 \pm 0.18$ & $12 \pm 1$ & 108 & $\left(<1 \times 10^{-7}\right)$ \\
NHF16 E6E7 & $26 \pm 3.2$ & 98 & $21 \pm 0.07$ & $19 \pm 9$ & 171 & $3.8 \times 10^{-5} \pm 2.7 \times 10^{-5}$ \\
NHF16 E6 & $19 \pm 1.4$ & 88 & $32 \pm 0.17$ & $24 \pm 4$ & 216 & $1.8 \times 10^{-5} \pm 2.3 \times 10^{-5}$ \\
NHF16 E7 & $22 \pm 1.5$ & 78 & $31 \pm 0.01$ & $11 \pm 3$ & 99 & $4.3 \times 10^{-6} \pm 2.6 \times 10^{-6}$ \\
\hline
\end{tabular}

a(PDL) Population doubling.

$\mathrm{b}(\mathrm{PE})$ Plating efficiency.

${ }^{c}\left(\mathrm{LD}_{50}\right)$ Concentration of PALA that permits $50 \%$ survival.

reaching confluence; they died (Fig. 2H). The cells formed a tight monolayer as they approached confluence, and mitotics could be detected, similar to those seen with the E6-expressing cells. However, after $\sim 3$ days at confluence these cells first became thin, elongated, and eventually rounded and refractile as they lifted from the plate and died, as measured by trypan blue uptake. Within $48 \mathrm{hr}$ the plate was completely clear of adherent cells.

\section{Cellular response to metabolic inhibitor}

To analyze amplification potential in these cells, we incubated them in the drug PALA under the standard conditions of the clonogenic assay (see Materials and methods). The normal human fibroblasts and those expressing the viral oncoproteins demonstrated dramatic differences in both the cellular response to the drug and the generation of PALA-resistant colonies. Uninfected NHF cells and neo-containing NHF exhibited a response to PALA that we have found is typical of normal human fibroblasts. The cells remained on the plate and failed to increase their cell number. There was no observable outgrowth of PALA-resistant colonies. Hence, uninfected NHF cells, as described previously (Tlsty 1990; Wright et al. 1990; Livingstone et al. 1992), and those containing the neo control lacked a detectable frequency of CAD gene amplification. When E6/E7- and E6-expressing cells were incubated in PALA, the vast majority gradually enlarged and sloughed from the plate over a period of 1-2 weeks, resulting in clearing of cells from the background. Infrequent, nondividing cells remained in the background while actively growing PALA-resistant colonies emerged during the selection process. Those cell populations containing the $\mathrm{E} 6 / \mathrm{E} 7$ proteins together or the E6 protein alone generated PALA-resistant colonies at a frequency of $3.8 \times 10^{-5}$ and $1.8 \times 10^{-5}$, respectively (Table 2; Fig. 3).

In contrast, when E7-expressing cells were incubated in the presence of PALA, there was a distinctly different response to the drug, which resulted in the clearing of cells from the plate within $\sim 6$ days. The E7-expressing cells became thin, elongated, and refractile, and after 3 days in PALA they began demonstrating a condensed, rounded morphology as they loosened from the substrate of the tissue culture plate. This morphological change is identical to that seen when these cells are held at confluence and is reminiscent of an apoptotic sequence of events that is initiated in certain cells under adverse conditions. The characteristic nuclear degradation ladder that occurs during apoptosis was not detected by gel electrophoresis (data not shown). At the termination of the PALA selection with the E7-expressing cells $1 \sim 6$ weeks later), there was no background of nondividing cells. The plate was cleared of cells except for the rare PALA-resistant colonies. Cells that expressed E7 alone generated PALA-resistant colonies at a frequency that was 10-fold lower than that observed for the E6/E7-expressing cells (Fig. 3 ). The frequencies of the generation of PALA-resistant colonies obtained with the viral oncoprotein-expressing cells are within the range of those observed previously in preneoplastic and neoplastic cell lines $\left(10^{-6}\right.$ to $\left.10^{-3}\right)$ (Sager et al. 1985; Otto et al. 1989; Tlsty et al. 1989; Jonczyk et al. 1993).

Whereas the drug resistance curves for the three HPV16-expressing cell populations revealed similar frequencies of generation of PALA-resistant colonies (Fig. 3), there were differences in the amount of time required for the formation of the visible colonies. The average time for isolation of NHF-16 E6/E7 PALA-resistant subclones was 3 weeks, compared with 4 and 6 weeks for the E6 and E7 PALA-resistant clones, respectively. The proliferative capacity of isolated subclones also differed, predictably as a direct reflection of the effect the HPV proteins on NHF life span in culture. The NHF16 E6/E7 PALA-resistant subclones grew very well. Ten E6/E7 PALA-resistant clones were chosen for further study and were found to senesce at $\sim 86$ PDL. PALA-resistant cells expressing only the E6 protein divided for fewer PDL than the subclones expressing both the viral oncoproteins. When expanded in culture they senesced at $\sim$ PDL 76. The NHF-16 E7 drug-resistant subclones had a diminished proliferative capacity when compared with the E6expressing subclones. The population ceased growth at $\sim$ PDL 66 . In the first set of experiments they ceased cell division before they could be expanded and examined for CAD gene copy number. We reinfected NHF cells at an earlier passage in subsequent experiments (passage 9) and were able to isolate PALA-resistant subclones for analysis of $\mathrm{CAD}$ gene copy number. These subclones 
White et al.
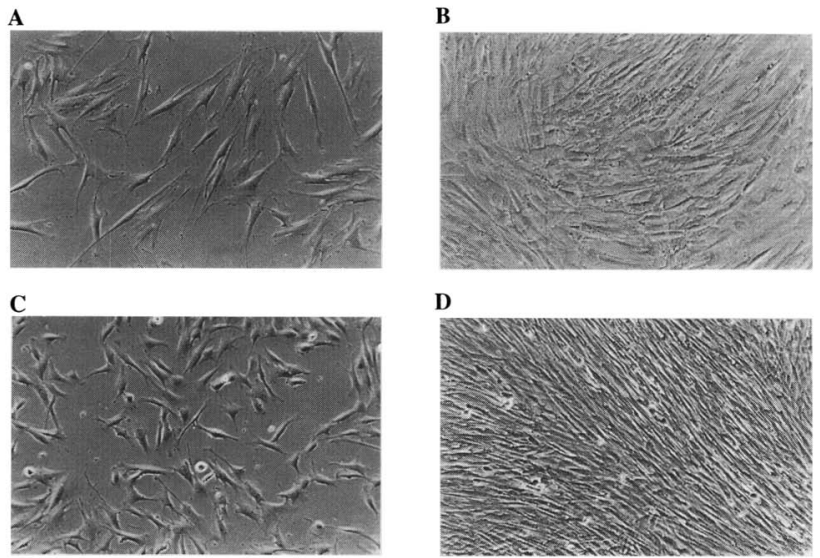

D
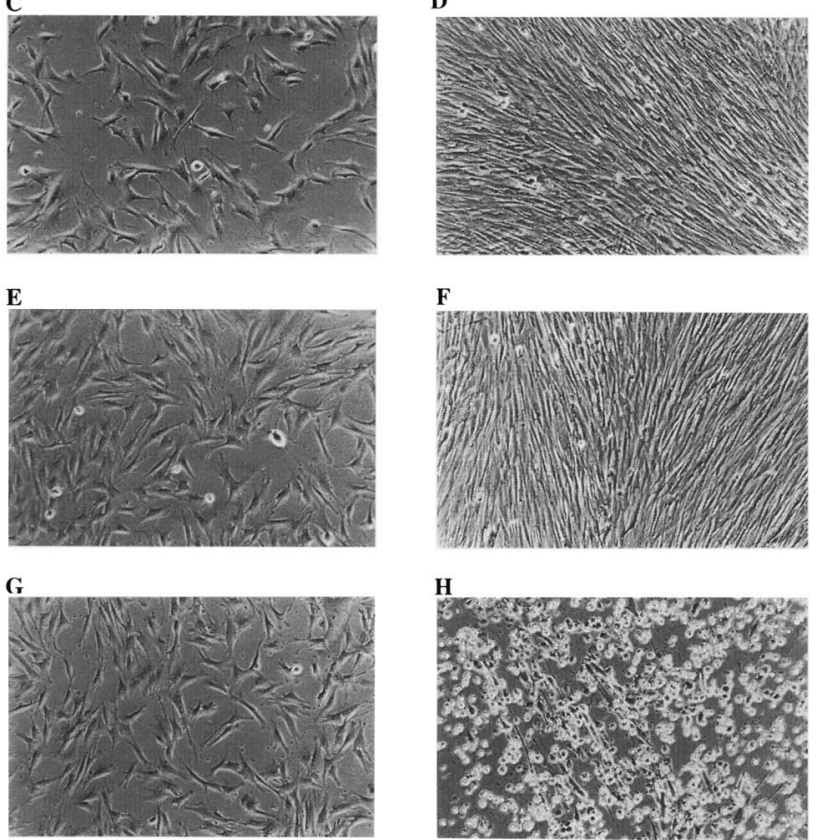

Figure 2. Morphology of normal and HPV-16 oncoprotein-expressing fibroblasts in the absence of PALA. Phase-contrast photographs of cells at subconfluence and confluence, grown in the absence of PALA, are shown. Cells were plated at $2 \times 10^{5}$ cells per $60-\mathrm{cm}$ petri dish and grown until they attained confluence. Cells were photographed at subconfluence after 3 days in culture and after 6 days at confluence. At subconfluence, the HPV protein-expressing cells were indistinguishable from each other [NHF16 E6/E7 $(C) ;$ NHF16 E6 $(E)$; NHF16 E7 $(G)]$ but distinct from the control cell populations [NHF $(A)$; NHFneo (not shown)|. NHF cells expressing the HPV proteins were smaller in size and had less extended processes compared with the parental cells. At confluence, control cell populations [NHF $(B)$; NHFneo [not shown)] were a tight monolayer of nondividing, viable cells. In contrast, NHF cells expressing both the $\mathrm{E} 6$ and $\mathrm{E} 7$ proteins or only the E6 protein continued to proliferate after reaching confluence as indicated by the presence of mitotic cells [NHF16E6/ E7 $(D)$; NHF16E6 $(F)]$. Massive cell death occurred in the E7expressing NHF after 2-3 days at confluence. Death was verified by cellular incorporation of the dye trypan blue. Magnification, $63 \mathrm{X}$.

ceased growth soon after isolation as well. In summary, all PALA-resistant clones were mortal.

As a control, NHF cells individually expressing low risk HPV-6 E6 and E7 proteins were assayed for PALAresistant colony formation. Studies of human cell transformation have shown that HPV-6 does not efficiently immortalize primary, human epithelial cells (Schlegel et al. 1988; Pecoraro et al. 1989; Halbert et al. 1992). There is no evidence for cellular degradation of $\mathrm{p} 53$ by HPV- 6 E6 (Scheffner et al. 1990; Werness et al. 1990; Crook et al. 1991), and the affinity of HPV-6 E7 protein for cellular retinoblastoma protein $(\mathrm{pRb})$ is $\sim 10$-fold lower than the affinity of HPV-16 E7 for pRb (Munger et al. 1989b; Barbosa et al. 1990; Gage et al. 1990; data not shown). In the presence of PALA, the NHF expressing the HPV-6 E6 and E7 proteins exhibited a phenotype typical of uninfected normal human fibroblasts. The cells enlarged, remained on the plate, and failed to proliferate. There was no cytocidal response nor PALA-resistant colony formation observed. These results suggested that the diminished ability of the type 6 viral proteins to efficiently bind specific cellular proteins (such as $\mathrm{p} 53, \mathrm{pRb}$, etc.) when compared with the type 16 oncoproteins correlated with the lack of ability to generate drug-resistant variants at a detectable frequency.

\section{Mechanism of drug resistance}

Several PALA-resistant subclones from each of the viral oncogene-expressing cell populations were analyzed for amplification of the CAD gene. Fluorescent in situ hybridization (FISH) analysis of the subclones verified intrachromosomal CAD gene amplification as the mechanism of resistance to PALA in the E6/E7- and E6-expressing cells. In all cases, the amplified copies were clustered with no distinct patterns observable. Representative hybridizations are seen in Figure 4, A and B. Further karyotypic analysis of two PALA-resistant subclones from each of the cell populations indicated a variety of chromosome rearrangements and telomeric

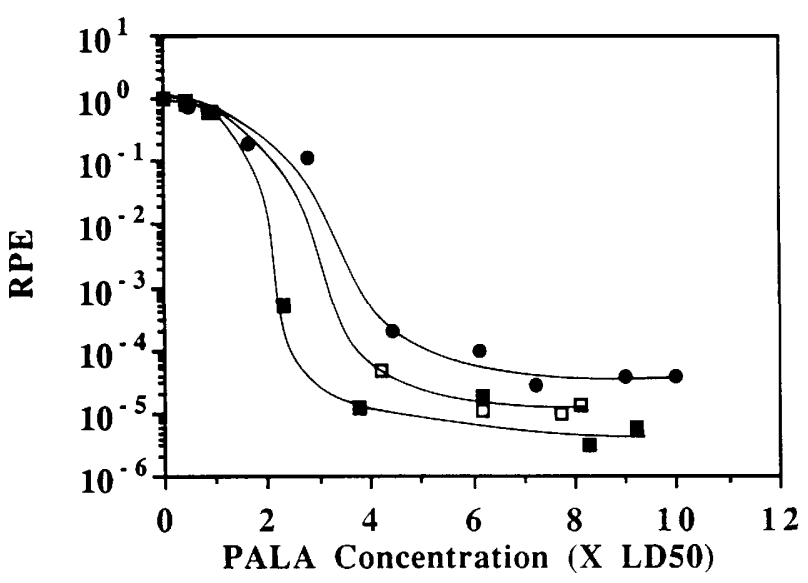

Figure 3. Determination of PALA resistance. Cells were plated at appropriate densities and placed in PALA concentrations indicated. When drug-resistant colony size exceeded 50 cells, colonies were fixed, stained, and counted. Relative plating efficiency (RPE) is the ratio of the percentage of cells surviving in PALA to the percentage of cells surviving in the absence of PALA. PALA resistance frequency was determined by the RPE value at $9 \times \mathrm{LD}_{50}$. The curves are an average of at least four determinations. (O) NHF-16 E6/E7; ( $\square$ ) NHF-16 E6; () NHF-16 E7. 

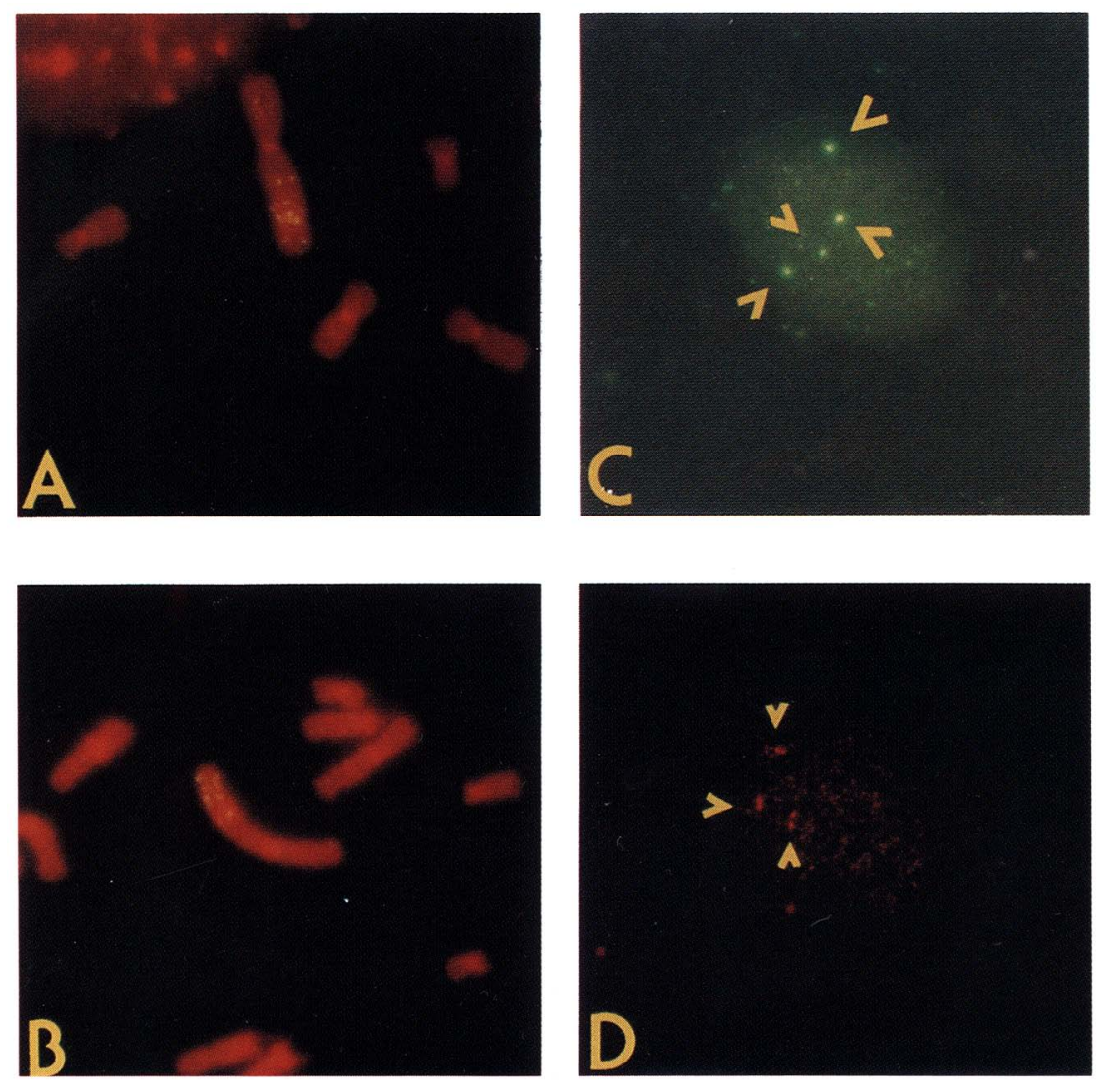

Figure 4. Fluorescence in situ hybridization of HPV-16 protein-expressing PALAresistant clones. Metaphase spreads from PALA-resistant subclones NHF16 E6/E7, clone 120-1 $(A)$, and NHF16 E6, clone 180-4 $(B)$, were hybridized to a human $\mathrm{CAD}$ gene probe to locate $\mathrm{CAD}$ gene sequences as described previously (Tlsty et al. 1992). The normal loci for the CAD gene is on chromosome 2. CAD gene amplification in the subclones was manifested as multiple copies of the gene in tandem arrays on a single chromosome arm. The PALA-resistant NHF16 E7 cells ceased proliferation when subcloned. Metaphase spreads were not obtained. Instead, interphase cells were analyzed for CAD gene and chromosome 2 centromere sequence copy number using different colored fluorochromes to determine whether the mode of drug resistance was gene amplification or multiple copies of chromosome 2. Equivalent $\mathrm{CAD}$ gene copies and centromere 2 sequences were observed in most clones, although in some clones centromere 2 sequences were more abundant than the CAD gene. Positive signals in the interphase cells are indicated by open arrowheads. (C) NHF16 E7, clone 108-2D centromere $2 ;(D)$ CAD gene associations (Table 1), similar to that seen in the unselected populations after extended passage in culture. Analysis of PALA-resistant subclones from the E7-expressing population was difficult because of their limited proliferative capacity and the difficulty in obtaining adequate metaphase spreads. Although complete karyotypic analysis was not possible, several samples were noted to have excessive numbers of chromosomes $(<100 \mid$. As an alternative to metaphase analysis, twocolor FISH analysis was performed on interphase preparations using probes specific for human chromosome 2 centromeric sequences and for the human CAD gene. Most often, multiple copies of centromeric chromosome 2 and of the CAD gene (four to seven copies) were detected indicating chromosome 2 aneuploidy as the primary mechanism of resistance to PALA (Fig. 4C,D). Hybridization with sequences specific for chromosome 6 also demonstrated multiple signals suggesting possible polyploidy (data not shown).

\section{Perturbed cell cycle progression}

Our previous studies had shown that normal human fibroblasts arrested in the $G_{1}$ and $G_{2}$ phases of the cell cycle when incubated with PALA (Livingstone et al. 1992). Figure 5, A-G, shows the cell cycle distribution of normal cells at various times after placement in drug 10 , $1,2,3,4,5,6$ days). Hours after exposure to the meta- bolic inhibitor PALA, an exponentially growing population of normal, diploid cells accumulated the majority of the cells in the $S$ phase of the cell cycle. This increased $S$ fraction gradually decreased until, at day 2 , there is a complete absence of cells in the $S$ phase indicating an arrest in cell cycle progression. The population was distributed between the $G_{1}$ and $G_{2}$ phases of the cell cycle for the duration of the selection. This temporal distribution of cells within each phase of the cell cycle is presented as a scatter plot (data directly from the flow cytometer) in Figure 5, A-G, and as a compilation over time in Figure $5 \mathrm{H}$. This graphic representation of the relative fractions of the population in $G_{1}, S$, or $G_{2} / M$ phase is helpful for comparing the response of normal cells in drug with that of the oncoprotein-expressing cells in drug. The status of multiple checkpoint functions can be monitored at one time. The white area on the graph in Figure $5 \mathrm{H}$ represents the percent of cells in the S-phase fraction, whereas the lower gray area represents those in $G_{1}$, and the upper dark area represents those in $\mathrm{G}_{2}$.

Deviations from this pattern were seen in the NHF cells expressing HPV-16 viral oncoproteins. In this assay, the various cell populations are pulsed with BrdU prior to harvesting. Only the cells that are actively incorporating nucleotides for synthesis of DNA during that period of time will appear in the S-phase fraction. Figure 6A demonstrates that after 2 days of incubation in PALA, 

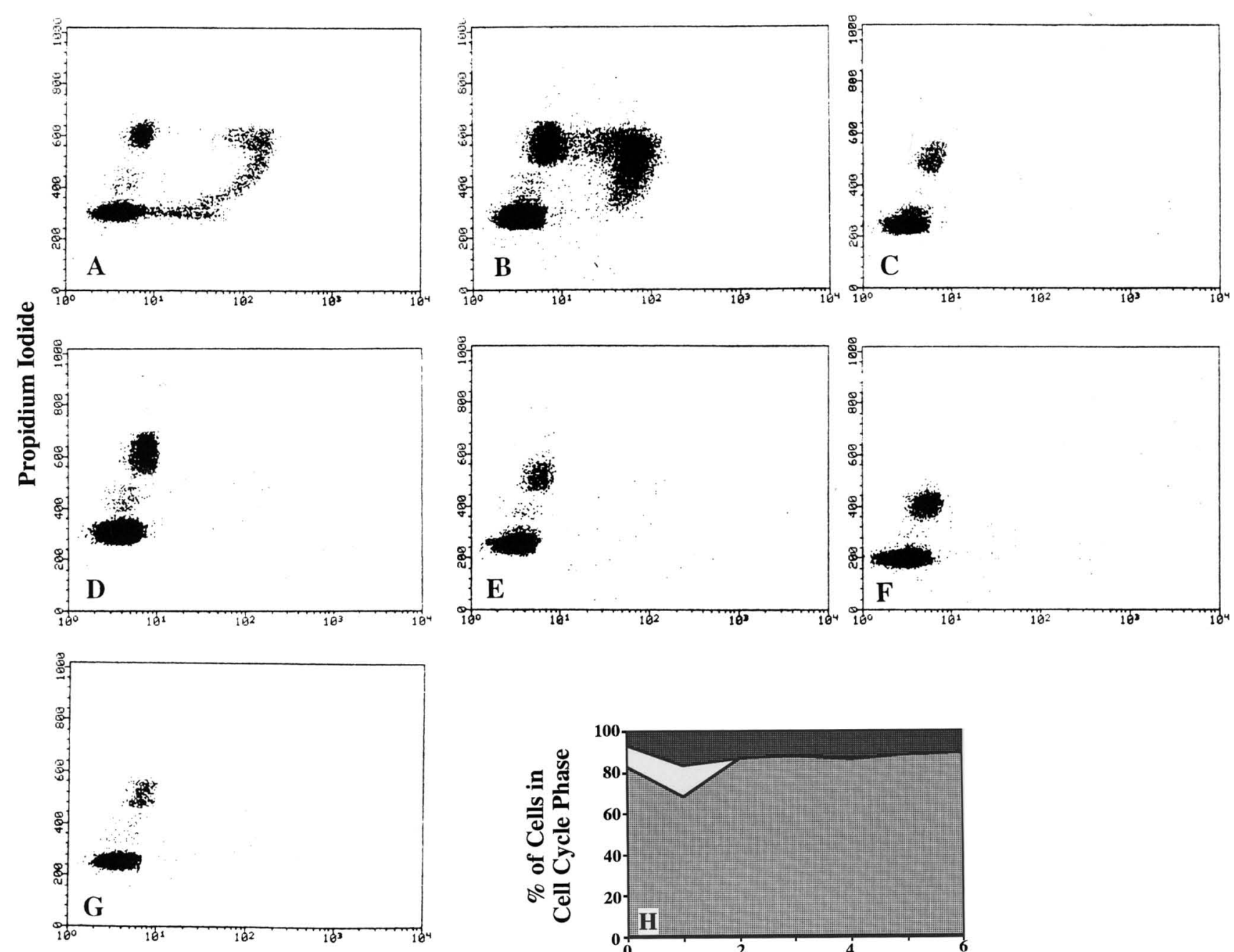

BrdU-FITC

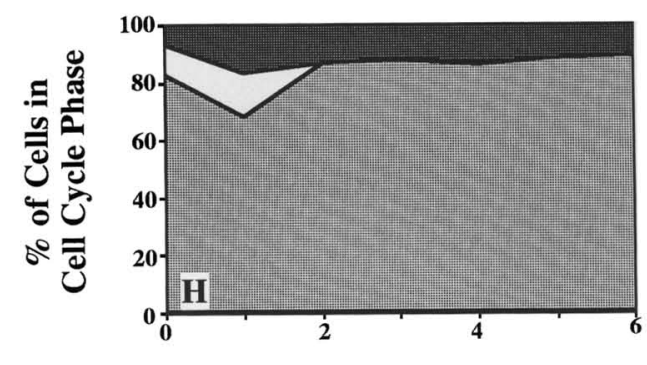

Days in PALA

Figure 5. Flow cytometric analysis of NHF cell population in PALA. Cells were labeled with BrdU, fixed, and stained with antiBrdU-FITC and propidium iodide, and analyzed using a Becton Dickinson FACScan instrument. The $x$-axis represents cells undergoing DNA synthesis. Cells at the right have more BrdU incorporated and are therefore in the $S$ phase of the cell cycle. The $y$-axis represents DNA content as measured by propidium iodide staining. The upper population has a $\mathrm{G}_{2}$ phase DNA content, and the lower population has a $G_{1}$ phase DNA content. $(A)$ NHF with no PALA exposure; $(B-G)$ NHF days 1-6 in PALA. The cell cycle data were compiled and presented in the form of an area graph, providing a characteristic cell cycle pattern that could be conveniently compared among the cells $(H)$. Each graph indicates the percentage of cells in each phase of the cell cycle (ordinate) as a function of time (axis; $0,1,2,3$, 4,5 , and 6 days in PALA). The $\mathrm{G}_{2}, \mathrm{~S}$, and $\mathrm{G}_{1}$ phases of the cell cycle are represented by the top, middle, and bottom areas of the graph, respectively. There was no significant portion of the parental NHF cells in S phase after 2 days in PALA.

none of the control cells are entering or actively participating in the $S$ phase of the cell cycle. This is represented by a lack of white area in the graph beyond 2 days. In contrast, at a similar point in time, those cells expressing HPV-16 E6 and E7 demonstrate that a large fraction of the cells are incorporating BrdU (Fig. 6B). These cells are distributed throughout the S-phase arc (seen in Fig. $5 \mathrm{~A}$ ) indicating that cells are actively synthesizing DNA days after the normal cells have ceased. Expression of the HPV-16 E6 or E7 individually (Figure 6C,D) also relieves checkpoint arrest but in reproducibly distinct patterns (compare S-phase fractions at day 2). Finally, analysis of cells expressing low risk HPV-6 proteins showed a complete arrest when the cells were incubated in PALA (Fig. 6E,F). These cells continue to respond to negative growth signals.

\section{Discussion}

In this study we demonstrated that distinct alterations in growth control circuitry can lead to different types of genomic instability. We began with cell populations that were isogenic and, by expression of HPV-16 E6 and E7 oncoproteins, contained disruptions in specific circuits 


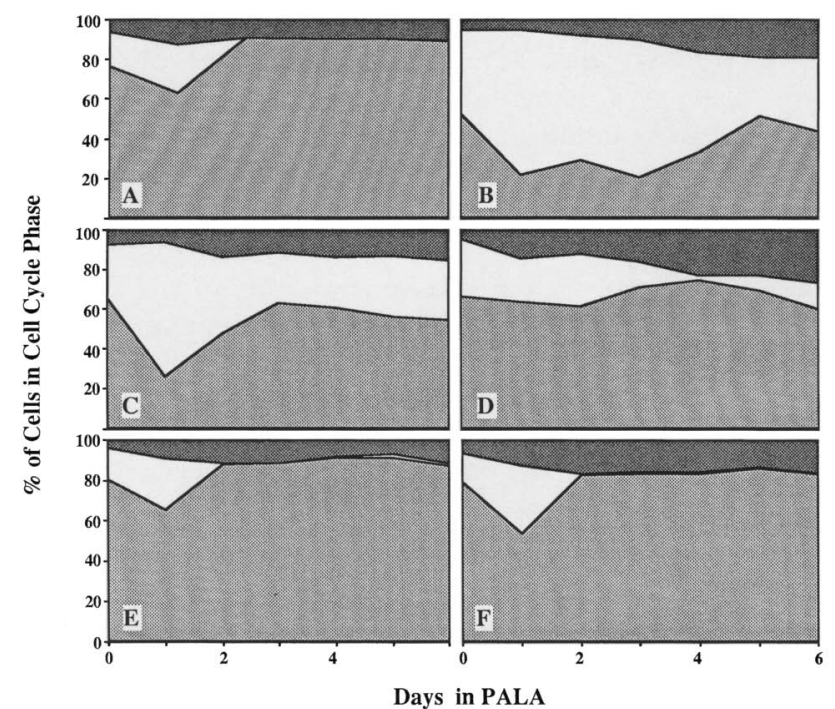

Figure 6. Flow cytometric analysis of NHF retrovirus-infected cell populations in PALA. Cells were treated and data are displayed as in Fig. 5. There was no significant portion of cells in $S$ phase after 2 days in PALA for cells expressing only the neomycin resistance gene and cells expressing the nononcogenic HPV-6 E6 or HPV-6 E7 proteins. All of the HPV-16 proteinexpressing cells continue to cycle in the presence of PALA, as indicated by a percentage of cells in the $\mathrm{S}$ phase throughout PALA exposure. $(A)$ NHF neo; $(B)$ NHF16 E6/E7; $(C)$ NHF16 E6; $(D)$ NHF16 E7; $(E)$ NHF6 E6; $(F)$ NHF6 E7.

that allowed cells to respond to altered growth conditions. It is important to note that the differential response of the cells depended on their need to respond to outside stimuli. The two stimuli described here are the negative growth signals that cells produced as they attained confluence or when the media was deficient in nutrients (in this case, nucleotide precursors). In the absence of either of these signals, each of the cell populations grew in an exponential fashion with no overt difficulties.

When exposed to the metabolic inhibitor PALA, normal human fibroblasts arrest in the $G_{1}$ and $G_{2}$ phases of the cell cycle. Each of the virally altered cell populations failed to arrest under these conditions and continued to cycle. While the majority of these cells died, a few generated drug-resistant colonies. In the cells where p53 function was compromised, cells with E6/E7 or E6 protein only, the majority of cycling cells died gradually, leaving the PALA-resistant colonies to expand. The altered karyotypes of these drug-resistant clones manifested CAD gene amplification in addition to other genomic changes. Rare PALA-resistant colonies arising from a background of gradually dying cells is the typical observation in most of the immortalized and tumorigenic cell lines that we have assayed to date. A plausible scenario begins to emerge as to how p53 participates in the generation of the rearrangements that fuel neoplasia. Cells suffer either endogenous or exogenous damage to their DNA, which brings about breakage of their genetic material. Broken chromosomes are usually detected in a normal cell, and cell cycle progression is arrested while the damage is repaired or the cell is removed. In cells that have mutated parts of the circuitry that sense, repair, or respond to damage in DNA, cell cycle progression fails to arrest. Broken chromosomes can replicate and fuse leading to the formation of dicentric chromosomes (Trask and Hamlin 1989; Toledo et al. 1992). The formation of a dicentric chromosome and the subsequent fusion-bridge-breakage cycle originally described by McClintock $>40$ years ago (McClintock 1939, 1942), generates duplications, deletions, and other abnormalities. These dicentric intermediates are seen quite often in cells with amplified genes (Smith et al. 1990; Windle et al. 1991; Toledo et al. 1992; Ma et al. 1993). These types of rearrangements activate oncogenes and inactivate tumor suppressor genes.

Whereas the elimination of checkpoint function of p53 could have accounted for the tolerance of broken chromosomes and the emergence of cells with amplified DNA sequences in the E6-expressing cells, the E7-expressing cells also generated PALA-resistant colonies. Here, the cellular and genomic response was totally different. The cells expressing only the E7 protein exhibited massive, immediate cell death after $\sim 3$ days in PALA, with very rare resistant colonies arising on a cleared background $\left(2 \times 10^{-6}\right.$ to $\left.6 \times 10^{-6}\right)$. These drug-resistant cells contained increased copies of $\mathrm{CAD}$ gene sequences, along with increased copies of chromosome 2 centromeric sequences, indicating that aneuploid cells had been generated. How expression of the E7 oncoproteins influences the formation of aneuploid cells is not known at the present time. A previous report indicated that HPV-16 E7 can induce cytogenetic abnormalities in immortalized keratinocytes (Hashida and Yasumoto 1991). As demonstrated in Figure 6D, these cells failed to arrest in cell cycle progression when placed in PALA even though they contained a wild-type p53 gene. This p53independent abrogation of cellular arrest, in some manner yet to be determined, leads to chromosomal consequences that are clearly distinct from those generated in cells that have eliminated $\mathrm{p} 53$. One may speculate that E7, which is known to bind cyclin A as well as cellular kinases (Dyson et al. 1992; Davies et al. 1993; Tommasino et al. 1993), disrupts cyclin homeostasis and leads to elimination of $G_{2}$ or relaxation of $G_{2} / M$ checkpoints. Because aneuploidy is one of the most common genomic aberrations seen in tumor cells, this mechanism deserves further investigation. Studies with polyoma $T$ antigen indicate that the expression of this gene in NHF cells also produces drug-resistant colonies, but the spectrum of genomic changes differs from those seen with HPV-16 E6/E7 (Schaefer et al. 1993). These results demonstrate that diverse perturbations of molecular pathways can have different effects on chromosomal architecture, and although there are functional similarities in some DNA tumor virus proteins (Vousden and Jat 1989; Werness et al. 1990|, there are also important differences among them.

These experiments demonstrated that expression of 
viral oncoproteins lead to the immediate acquisition of the ability to amplify the CAD gene sequences. These cells relinquished their control of genomic integrity prior to immortalization, clearly indicating that this change is not necessary. Because previous studies with Syrian hamster epithelial cells identified immortal cells that lack the ability to amplify (sup ${ }^{+}$cells) (Jonczyk et al. 1993), and this study documented mortal cells that have the ability to amplify, it is clear that immortalization of mammalian cells is neither necessary nor sufficient for amplification to occur. Our observation of amplification in these mortal cells also addressed our initial question as to when the virally infected cells acquired the ability to amplify or undergo genomic rearrangements. This change must occur immediately with expression of the E6/E7 genes.

Strikingly, the biology of cervical carcinomas points to the expression of E6 and E7 as important in tumor progression. The high risk viruses are episomal in benign lesions, and in this state, the product of the HPV E2 ORF generates a protein that suppresses transcription of the E6 and E7 genes. Little protein is made. In carcinomas, the high risk viruses are usually found integrated into the host genome (Durst et al. 1985; Pater and Pater 1985). This integration event is accompanied by a change in transcriptional activity and pattern. Reproducibly, this integration results in the disruption of the coding region between the E1 and E2 genes and consequently allows for the more efficient expression of E6 and E7 transcription and subsequent protein production (Romanczuk and Howley 1992). Whereas in the episomal state, the entire spectrum of viral proteins that are used for replication, capsid formation, and so on, are expressed, in the integrated state, the E6 and E7 viral oncogenic products become the dominant transcripts. Our data demonstrate that expression of these oncoprotein products and their concomitant functional inactivation of cellular proteins results in genomic instability. The generation of chromosomal rearrangements ostensibly allows progression of the malignant state.

In addition to mediating growth arrest, p53 is implicated in another process that may serve to protect the organism from a defective genome, the triggering of apoptosis, an active death process (Debbas and White 1993; Yonish-Rouach et al. 1993). Our observations with HPV$16 \mathrm{E} 6 / \mathrm{E} 7$ expression in human cells parallel recent work with adenovirus E1A/E1B in a striking manner, suggesting further functional analogies between the various viral oncoproteins. The E6 and E1B oncoproteins are functional homologs while the E7 and E1A oncoproteins share DNA sequence and functional homology. Cells expressing E1A alone show a rapid loss of viability immediately upon achieving saturation density. Those cells expressing both E1A and E1B do not demonstrate this rapid cytocidal response (Rao et al. 1992). Transformation of rodent cells by the adenovirus oncoproteins E1A and E1B requires two events, E1A-dependent induction of proliferation and E1B-dependent suppression of apoptosis. The sole expression of E1A results in efficient initiation of focus formation, but the cells cannot sustain proliferation. They degenerate and die. Cell death is mediated through an up-regulation of p53 that results in the production of a cytocidal and DNA degradation phenotype. If $\mathrm{p} 53$ is functionally removed from these cells, as when E1B is coexpressed, the apoptotic pathway can no longer be induced. The E1A/E1B-expressing cells can now produce transformed foci with a high frequency that have a good probability of immortalizing. In our system the sole expression of the E7 gene in challenged cells resulted in a cytocidal response and the formation of drug-resistant colonies that cannot sustain proliferation. If $\mathrm{p} 53$ is functionally removed from these cells, as when E6 is coexpressed, the cytocidal response is no longer induced and the drug-resistant colonies grow in a healthy manner. In each case, a negative growth signal (confluence in the rodent cells and nutrient deprivation or confluence in the human fibroblasts) elicited a physiological response that is similar in each cell type and dependent on the genotype of the cell.

Finally, the studies presented here may provide the biological basis for the differences between high risk and low risk HPV types in terms of neoplastic transformation. Both the high risk and low risk viruses cause hyperproliferation in cells, yet only the high risk viruses produce cellular variants that can escape differentiation, immortalize, and progress to malignancy (zur Hausen 1991). The high risk viruses are known to be much more efficient in binding and degrading $\mathrm{p} 53$ than their low risk counterparts (Werness et al. 1990; Scheffner et al. 1990; Crook et al. 1991). Likewise, the high risk E7 protein binds $\mathrm{pRB}$ with a 10-fold greater affinity than the low risk type (Munger et al. 1989a). We propose that one of the basic differences between these two types of viruses is their maintenance of genomic integrity. Two pieces of data demonstrated that cells infected with low risk virus maintained their genomic integrity while those expressing the high risk virus did not. First, no PALA-resistant colonies were generated when cells infected with HPV-6 E6 or E7 were challenged with drug. The frequency was at least two orders of magnitude lower than measured with HPV-16. Second, the cells expressing the low risk HPV-6 E6 anc E7 genes can arrest in cell cycle progression when exposed to PALA or confluence, demonstrating that these cells sense negative growth signals and respond in an appropriate manner; they arrest. In contrast, the biology of the cells containing the high risk virus pointed to the involvement of $\mathrm{E} 6$ and $\mathrm{E} 7$ in the loss of genomic integrity and in tumor progression.

\section{Materials and methods}

Cell populatons and culture conditions

All cells were grown in $\alpha$ minimal essential medium minus nucleosides and deoxyribonucleosides, but containing glutamine and $10 \%$ dialyzed fetal bovine serum (JRH Biosciences). Primary, human foreskin fibroblasts were obtained from Dr. M. Cordiero-Stone (University of North Carolina at Chapel Hill). At PDL 33 or 36, cells in log phase growth were infected with retroviral vectors containing only the neomycin resistance gene (vector LXSN), vectors containing the neomycin gene and HPV- 
16 ORFs for the E6 and/or E7 proteins (LXSN16E6E7, LXSN16E6, or LXSN16E7), or vectors containing the neomycin resistance sequences and HPV-6 E6 or E7 ORFs (LXSN6E6 and LXSN6E7). The vectors were a gift from Dr. Denise Galloway (Fred Hutchinson Cancer Center, Seattle, WA) and have been described previously (Halbert et al. 1991).

\section{Retroviral infections}

Retroviruses containing the various vectors were produced by the murine cell line PA317. The procedure for retroviral infection entailed the following. NHF cells were incubated for 8-10 $\mathrm{hr}$ in filtered, polybrene-supplemented medium from the PA317 cells containing the appropriate retrovirus. The NHF cells were trypsinized and seeded at varying densities in medium containing $500 \mathrm{mg} / \mathrm{ml}$ of G418 sulfate (Geneticin, GIBCO-BRL Laboratories). G418-resistant colonies were visible in $\sim 1$ week and were pooled for each cell population. Cell populations were designated NHF neo, NHF16 E6/E7, NHF16 E6, NHF16 E7, NHF 6E6, and NHF 6E7.

\section{$P D L$ time determination}

PDL time for each cell population was determined by plating $\sim 5 \times 10^{4}$ cells in each of ten $100-\mathrm{mm}$ petri dishes. Cell counts from two dishes were averaged daily, beginning $24 \mathrm{hr}$ postplating, and plotted as a function of time. Total PDLs were determined by plating a known cell number and counting cells at each passage until senescence.

\section{Karyotypic analysis}

The procedure used to obtain G-banded chromosomes was described previously (Livingstone et al. 1992). Each cell population was analyzed in the absence of PALA. PALA-resistant NHF16 E6E7 and NHF16 E6 subclones were also analyzed.

\section{Clonogenic assay}

The assay is used to determine gene amplification frequency and has been described previously (Otto et al. 1989). Briefly, cells were grown in the presence of the drug PALA, which specifically inhibits the aspartate transcarbamylase activity of the multifunctional CAD enzyme involved in de novo pyrimidine synthesis. PALA selects for cells with CAD gene amplification. Cells were plated in $100-\mathrm{mm}$ dishes at densities of $2 \times 10^{2}$ to $2 \times 10^{4}$ cells and in $150-\mathrm{mm}$ dishes at densities of $2 \times 10^{5}$ cells. PALA-resistant colonies of 50 cells or greater were detectable after 2-6 weeks and were fixed, stained, and counted. Plating efficiency, the ratio of the number of colonies obtained without PALA selection to the number of cells seeded (100\% survival), and $\mathrm{LD}_{50}$, the concentration of PALA that allows $50 \%$ survival, were determined for each cell population so that direct comparisons among the cells could be made. Amplification frequency was expressed as the number of PALA-resistant colonies at $9 \times$ $\mathrm{LD}_{50}$ relative to the plating efficiency of the cell population. PALA was obtained from the Drug Evaluation Branch of the National Cancer Institute.

\section{FISH}

PALA-resistant subclones $\left(9 \times \mathrm{LD}_{50}\right.$ and above) were analyzed for CAD gene amplification by FISH as described previously (Tlsty et al. 1992). The human CAD probe was a kind gift from Dr. J. Davidson (University of Kentucky, Lexington). Probe for centromeric sequences of chromosome 2 was purchased from Oncor.

\section{Cell cycle analysis}

Cells were plated in regular growth medium or medium containing PALA at $9 \times \mathrm{LD}_{50}$ for the respective cell strain. A modification of the cell cycle analysis used by Kastan and co-workers was used (Kastan et al. 1991). On days 0-6, BrdU was added to a $\log$ phase population of cells at a concentration of $10 \mathrm{mM}$, and after $4-5 \mathrm{hr}$ the cells were trypsinized and counted, and then fixed using $1.5 \mathrm{ml}$ of cold phosphate-buffered saline and 3 $\mathrm{ml}$ of cold $95 \%$ EtOH per $10^{6}$ cells. The fixed cells were processed as follows for propidium iodide staining. Two million fixed cells were centrifuged for $5 \mathrm{~min}$ at $1200 \mathrm{rpm}$ using a Sorvall $\mathrm{HT} 1000 \mathrm{~B}$ rotor at $4^{\circ} \mathrm{C}$, and the pellet was resuspended with vortexing in $3 \mathrm{ml}$ of $0.08 \%$ pepsin. After a 20 -min incubation at $37^{\circ} \mathrm{C}$, the nuclei were centrifuged as above and resuspended in $1.5 \mathrm{ml}$ of $2 \mathrm{~N} \mathrm{HCl}$ while vortexing. After $20 \mathrm{~min}$ at $37^{\circ} \mathrm{C}, 3 \mathrm{ml}$ of $0.1 \mathrm{M}$ sodium borate was added to neutralize the nuclei and they were centrifuged for $5 \mathrm{~min}$. The pellet was resuspended in $2 \mathrm{ml}$ of IFA ( $10 \mathrm{~mm}$ HEPES at $\mathrm{pH} 7.4,150 \mathrm{~mm} \mathrm{NaCl}, 4 \%$ serum, $0.1 \%$ sodium azide) with $0.5 \%$ Tween 20 and centrifuged as above. The nuclear pellet was resuspended in $100 \mu \mathrm{l}$ of a 1:5 dilution of anti-BrdU fluorescein isothiocynate-conjugated antibody (Becton Dickinson) in IFA. After a 30-min incubation on ice in the dark, $2 \mathrm{ml}$ of IFA with $0.5 \%$ Tween 20 was added and the tubes were centrifuged for $5 \mathrm{~min}$. The nuclei were suspended in $500 \mu \mathrm{l}$ of IFA, RNase A (Sigma) was added to $5 \mu \mathrm{g} / \mathrm{ml}$, propidium iodide (Aldrich Chemical Co.) was added to $50 \mu \mathrm{g} / \mathrm{ml}$, and incubation proceeded at $37^{\circ} \mathrm{C}$ for $15 \mathrm{~min}$. The nuclei were kept in the dark, on ice for at least $15 \mathrm{~min}$. Cell cycle analysis was then performed using a Becton Dickinson FACScan instrument.

\section{Immunoprecipitation of viral and cellular proteins}

Cells $\left(2 \times 10^{6}\right)$ were incubated in methionine and cysteine-free Dulbecco's modified Eagle medium (DMEM), for $1 \mathrm{hr}$ at $37^{\circ} \mathrm{C}$ and were then labeled for $3 \mathrm{hr}$ with $80 \mu \mathrm{Ci} / \mathrm{ml}$ of $\operatorname{Tran}^{35} \mathrm{~S}$-label $170 \% \mathrm{~L}-\left[{ }^{35} \mathrm{~S}\right]$ methionine and $\mathrm{L}-\left[{ }^{35} \mathrm{~S}\right]$ cysteine, ICN. Incubation in $800 \mu$ l of lysis buffer $(20 \mathrm{~mm}$ Tris at $\mathrm{pH} 7.4,250 \mathrm{~mm} \mathrm{NaCl}, 0.5 \%$ NP-40, $1 \mathrm{mM}$ EDTA, $50 \mu \mathrm{g} / \mathrm{ml}$ of leupeptin, $30 \mu \mathrm{g} / \mathrm{ml}$ of aprotinin/ for $10 \mathrm{~min}$ at $4^{\circ} \mathrm{C}$ was followed by centrifugation at 14,000 $\mathrm{rpm}$ for $30 \mathrm{~min}$ to remove cellular debris. Lysates were precleared by absorption with Sansorbin (Calbiochem) for $30 \mathrm{~min}$ on ice and microcentrifuged for $15 \mathrm{~min}$. Equivalent trichloroacetic acid precipitable counts $\left(5 \times 10^{7}\right)$ of radioactive protein were immunoprecipitated with protein A-Sepharose coated with mouse anti-HPV-18/16E6 (Oncogene Science), anti-HPV16E7 (Denise Galloway), anti-human p53 protein (p53 Ab-5, Oncogence Science), or anti-retinoblastoma protein antibody ( $R B$ $\mathrm{Ab}-\mathrm{l}$, Oncogene Sciencel for $2 \mathrm{hr}$. Immune complexes were washed four times in wash buffer $(20 \mathrm{~mm}$ Tris at $\mathrm{pH} 7.4,150 \mathrm{~mm}$ $\mathrm{NaCl}, 0.5 \% \mathrm{NP}-40,0.1 \% \mathrm{SDS}$ ), twice in PBS, released from the beads by heating to $95^{\circ} \mathrm{C}$, and separated on $12 \%$ SDS-polyacrylamide gels. Gels were fixed, treated with Amplify (Amersham), dried, and exposed to $\mathrm{x}$-ray film.

\section{Acknowledgments}

We thank Drs. M. Cordiero-Stone and Denise Galloway for generously providing cells and retroviral constructs, respectively. We thank Drs. B. Weissman, P. Howley, K. Munger, L. Hartwell, R. Weinberg, T. Gilmer, C. Walker, and the members of the Tlsty laboratory for critical reading of the manuscript and en- 
couragement. We thank H. Roelofs for assistance with two color fluorescence studies and B. Poulose for assistance with presentation of cell cycle data. This research was supported by $\mathrm{Na}$ tional Institutes of Health grant (CA 51912) to T.D.T.

The publication costs of this article were defrayed in part by payment of page charges. This article must therefore be hereby marked "advertisement" in accordance with 18 USC section 1734 solely to indicate this fact.

\section{References}

Aurias, A. 1993. Acquired chromosomal aberrations in normal individuals. In The causes and consequences of chromosomal aberrations (ed. I.R. Kirsch), pp.125-139. CRC Press, Inc., Ann Arbor, MI.

Baker, C.C., W.C. Phelps, V. Lindgren, M.J. Braun, M.A. Gondas, and P.M. Howley. 1987. Structural and translational analysis of human papillomavirus type 16 sequences in cervical carcinoma cell lines. J. Virol. 61: 962-971.

Barbosa, M.S., C. Edmonds, C. Fisher, J.T. Schiller, D.R. Lowy, and K.H. Vousden. 1990. The region of the HPV E7 oncoprotein homologous to adenovirus $\mathrm{Ela}$ and SV40 large $\mathrm{T}$ antigen contains separate domains for $\mathrm{Rb}$ binding and casein kinase II. $E M B O$ I. 9: 153-160.

Crook, T., J.A. Tidy, and K.H. Vousden. 1991. Degradation of p53 can be targeted by HPV E6 sequences distnict from those required for p53 binding and trans-activation. Cell 67: 547556.

Davies, R., R. Hicks, T. Crook, J. Morris, and K. Vousden. 1993. Human papillomavirus type $16 \mathrm{E} 7$ associates with a histone H1 kinase and with p107 through sequences necessary for transformation. I. Virol. 67: 2521-2528.

Debbas, M. and E. White. 1993. Wild-type p53 mediates apoptosis by E1A, which is inhibited by E1B. Genes \& Dev. 7: 546-554.

Dhanwada, K.R., V. Veerisetty, F. Zhu, A. Razzaque, K.D. Thompson, and C. Jones. 1992. Characterization of primay human fibroblasts transformed by human papillomavirus type 16 and herpes simplex type 2 DNA sequences. I. Gen. Virol. 73: 791-799.

Durst, M., A. Kleinheinz, M. Hotz, and L. Gismann. 1985. The physical state of human papillomavirus type 16 DNA in benign and malignant genital tumours. Virology 66: 15151522.

Dyson, N., P.M. Howley, K. Munger, and E. Harlow. 1989. The human papillomavirus-16 E7 onco protein is able to bind to the retinoblastoma gene product. Science 243: 934-937.

Dyson, N., P. Guida, K. Munger, and E. Harlow. 1992. Homologous sequences in adenovirus E1A and human papillomavirus E7 proteins mediate interaction with the same set of cellular proteins. I. Virol. 66: 6893-6902.

Gage, J.R., C. Meyers, and F.O. Wettstein. 1990. The E7 proteins of the nononcogenic human papillomavirus type $6 \mathrm{~b}$ (HPV6b) and of the oncogenic HPV-16 differ in retinoblastoma protein binding and other properties. J. Virol. 46: 723-730.

Halbert, C.L., G.W. Demers, and D.A. Galloway. 1991. The E7 gene of human papillomavirus type 16 is sufficient for immortalization of human epithelial cells. J. Virol. 65: 473478.

Halbert, C.L., G.W. Demers, and D.A. Galloway. 1992. The E6 and E7 genes of human papillomavirus type 6 have weak immmortalizing activity in human epithelial cells. $J$. Virol. 66: $2125-2134$.

Hartwell, L.H. and T.A. Weinert. 1989. Checkpoints: Controls that ensure the order of cell cycle events. Science 246: 629-
633.

Hashida, T. and S. Yasumoto. 1991. Induction of chromosomal abnormalities in mouse and human epidermal keratinocytes by the human papillomavirus type 16 E7 oncogene. $J$. Gen. Virol. 72: 1569-1577.

Hawley-Nelson, P., K.H. Vousden, N.L. Hubbert, D.R. Lowy, and J.T. Schiller. 1989. HPV16 E6 and E7 proteins cooperate to immortalize human foreskin keratinocytes. EMBO $J$. 8: 3905-3910.

Jonczyk, P., A. White, K. Lum, J.C. Barrett, and T.D. Tlsty. 1993. Amplification potential in preneoplastic and neoplastic Syrian hamster embryo fibroblasts transformed by various carcinogens. Cancer Res. 53: 3098-3102.

Kastan, M.B., O. Onyekwere, D. Sidransky, B. Vogelstein, and R.W. Craig. 1991. Participation of p53 protein in the cellular response to DNA damage. Cancer Res. 51: 6304-6311.

Kuerbitz, S.J., B.S. Plunkett, W.V. Walsh, and M.B. Kastan. 1992. Wild-type p53 is a cell cycle checkpoint determinant following irradiation. Proc. Natl. Acad. Sci. 89: 7491-7495.

Livingstone, L.R., A. White, J. Sprouse, E. Livanos, T. Jacks, and T.D. Tlsty. 1992. Altered cell cycle arrest and gene amplification potential accompany loss of wild-type p53. Cell 70: 923-935.

Ma, C., S. Martin, B. Trask, and J.L. Hamlin. 1993. Sister chromatid fusion initiates amplification of the dihydrofolate reductase gene in Chinese hamster cells. Genes \& Dev. 7: 605-620.

McClintock, B. 1939. The behavior in sucessive nuclear divisions of a chromosome broken at meiosis. Proc. Natl. Acad. Sci. 25: 405-416.

- 1942. The fusion of broken ends of chromosomes following nuclear fusion. Proc. Nat1. Acad. Sci. 28: 458-463.

Munger, K., W.C. Phelps, V. Bubb, P.M. Howley, and R. Schlegel. 1989a. The E6 and E7 genes of the human papillomavirus type 16 together are necessary and sufficient for trans formation of primary human keratinocytes. I. Virol. 63: $4417-4421$.

Munger, K., B.A. Werness, N. Dyson, W.C. Phelps, E. Harlow, and P.M. Howley. 1989b. Complex formation of human papillomavirus $E 7$ proteins with the retinoblastoma tumor suppressor gene product. EMBO J. 8: 4099-4105.

Otto, E., S. McCord, and T.D. Tlsty. 1989. Increased incidence of $\mathrm{CAD}$ gene amplification in tumorigenic rat lines as an indicator of genomic instability of neoplastic cells. $/$. Biol. Chem. 264: 3390-3396.

Pater, M.M. and A. Pater. 1985. Human papillomavirus types 16 and 18 sequences in carcinoma cell lines of the cervix. $\mathrm{Vi}$ rology 145: 313-318.

Pecoraro, G., D. Morgan, and V. Defendi. 1989. Differential effects of human papillomavirus type 6,16 , and 18 DNAs on immortalization and transformation of human cervical epithelial cells. Proc. Natl. Acad. Sci. 86: 563-567.

Rao, L., M. Debbas, P. Sabbatini, D. Hockenbery, S. Korsmeyer, and E. White. 1992. The adenovirus E1A proteins induce apoptosis, which is inhibited by the E1B 19-kDa and Bcl-2 proteins. Proc. Natl. Acad. Sci. 89: 7742-7746.

Romanczuk, H. and P.M. Howley. 1992. Disruption of either the E1 or the E2 regulatory gene of human papillomavirus type 16 increases viral immortalization capacity. Proc. Natl. Acad. Sci. 89: 3159-3163.

Sager, R., I. Gadi, L. Stephens, and C.T. Grabowy. 1985. Gene amplification: An example of accelerated evolution in tumorigenic cells. Proc. Natl. Acad. Sci. 82: 7015-7019.

Schaefer, D.I., E.M. Livanos, A.E.White, and T.D. Tlsty. 1993. Multiple mechanisms of $\mathrm{N}$-(phosphonoacetyl)-L-aspartate drug resistance in SV40-infected precrisis human fibroblasts. 
Cancer Res. 53: 4946-4951.

Scheffner, M., B.A. Werness, J.M. Huibregtse, A.J. Levine, and P.M. Howley. 1990. The E6 oncoprotein encoded by human papillomavirus types 16 and 18 promotes the degradation of p53. Cell 63: 1129-1136.

Schlegel, R., W.C. Phelps, Y.L. Zhang, and M. Barbosa. 1988. Quantitative keratinocyte assay detects two biological activities of human papillomavirus DNA and identifies viral types associated with cervical carcinoma. EMBO I. 7:31813187.

Schwarz, E., U.K. Freese, L. Gissman, W. Mayer, B. Roggenbuck, A. Stremlau, and H. zur Hausen. 1985. Structure and transcription of human papillomavirus sequences in cervical carcinoma cells. Nature 314: 111-114.

Shay, J.W., W.E. Wright, D. Brasiskyte, and B.A. Van Der Haegen. 1993. E6 of human papillomavirus type 16 can overcome the $\mathrm{Ml}$ stage of immortalization in human mammary cells but not in human fibroblasts. Oncogene 8: 1407-1413.

Smith, K.A., P.A. Gorman, M.B. Stark, R.P. Groves, and G.R. Stark. 1990. Distinctive chromosomal structures are formed very early in the amplification of CAD genes in Syrian hamster cells. Cell 63: 1219-1227.

Smotkin, D. and F.O. Wettstein. 1986. Transcription of human papillomavirus type 16 early genes in a cervical cancer and a cancer-derived cell line and identification of the $\mathrm{E} 7$ protein. Proc. Natl. Acad. Sci. 83: 4680-4684.

Tlsty, T.D. 1990. Normal diploid human and rodent cells lack a detectable frequency of gene amplification. Proc. Natl. Acad. Sci. 87: 3132-3136.

Tlsty, T.D., B. Margolin, and K. Lum. 1989. Differences in the rates of gene amplification in nontumorigenic and tumorigenic cell lines as measured by Luria-Delbruck fluctuation analysis. Proc. Natl. Acad. Sci. 86: 9441-9445.

Tlsty, T.D., A. White, and J. Sanchez. 1992. Suppression of gene amplification in human cell hybrids. Science 255: 14251427.

Toledo, F., D. Le Roscouet, G. Buttin, ad M. Debatisse. 1992. Co-amplified markers alternate in megabase long chromosomal inverted repeats and cluster independently in interphase nuclei at early steps of mammalian gene amplification. $E M B O$ \%. 11: 2665-2673.

Tommasino, M., J.P. Adamczewski, F. Carlotti, C.F. Barth, R. Manetti, M. Contorni, F. Cavalieri, T. Hunt, and L. Crawford. 1993. HPV16 E7 protein associates with the protein kinase p33CDK2 and cyclin A. Oncogene 8: 195-202.

Trask, B. and J. Hamlin. 1989. Early dihydrofolate reductase gene amplification events in CHO cells usually occur on the same chromosome arm as the original locus. Genes \& Dev. 3: 913-1920.

Vousden, K.H. and P.S. Jat. 1989. Functional similarity between HPV16 E7, SV40 large T and adenovirus Ela proteins. Oncogene 4: 153-158.

Watanabe, S., T. Kanda, and K. Yoshiike. 1989. Human papillomavirus type 16 transformantion of primary human embryonic fibroblasts requires expression of open reading frames E6 and E7. $/$. Virol. 63: 965-969.

Werness, B.A., A.J. Levine, and P.M. Howley. 1990. Association of human papillomavirus types 16 and $18 \mathrm{E} 6$ proteins with p53. Science 248: 76-79.

Wilczynski, S.P., L. Pearlman, and J. Walker. 1988. Identification of HPV 16 early genes retained in cervical carcinomas. Virology 166: 624-627.

Windle, B., B.W. Draper, Y. Yin, S. O'Gorman, and G.M. Wahl. 1991. A central role for chromosome breakage in gene amplification, deletion formation, and amplicon integration. Genes \& Dev. 5: 160-174.
Wright, J.A., H.S. Smith, F.M. Watt, M.C. Hancock, D.L. Hudson, and G.R. Stark. 1990. DNA amplification is rare in normal human cells. Proc. Natl. Acad. Sci. 87: 1791-1795.

Yin, Y., M.A. Tainsky, F.Z. Bischoff, L.C. Strong, and G.M. Wahl. 1992. Wild type p53 restores cell cycle control and inhibits gene amplification in cells with mutant p53 alleles. Cell 70: 937-948.

Yonish-Rouach, E., D. Grinwald, S. Wilder, A. Kimchi, E. May, J. Lawrence, P. May, and M. Oren. 1993. p53-mediated cell death: Relationship to cell cycle control. Mol. Cell. Biol. 13: 1415-1423.

zur Hausen, H. 1991. Human papillomaviruses in the pathogenesis of anogential cancer. Virology 184: 9-13.. 


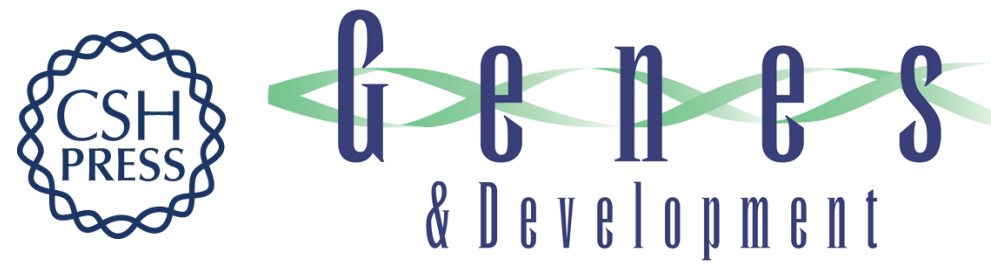

\section{Differential disruption of genomic integrity and cell cycle regulation in normal human fibroblasts by the HPV oncoproteins.}

A E White, E M Livanos and T D TIsty

Genes Dev. 1994, 8:

Access the most recent version at doi:10.1101/gad.8.6.666

References This article cites 52 articles, 30 of which can be accessed free at:

http://genesdev.cshlp.org/content/8/6/666.full.html\#ref-list-1

License

Email Alerting

Service

Receive free email alerts when new articles cite this article - sign up in the box at the top right corner of the article or click here.

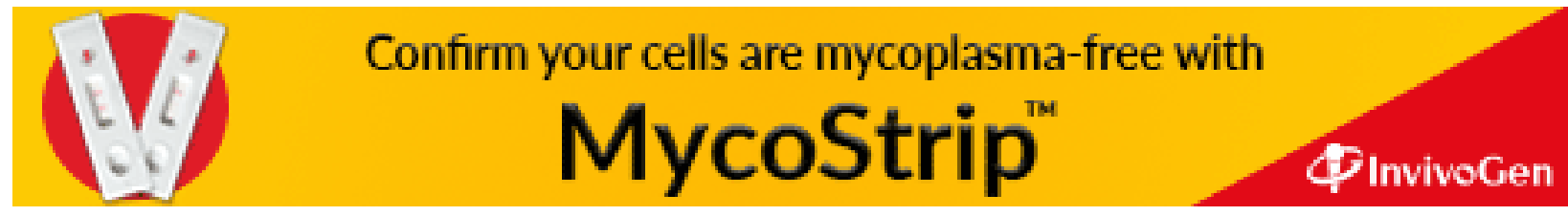

